\title{
The Effect of 3-Dimensional Posture Correction Exercise Program Incorporating PNF Respiratory Muscle Strengthening Exercise on the Spinal Alignment and the Trunk Expansion in Patients with Idiopathic Scoliosis
}

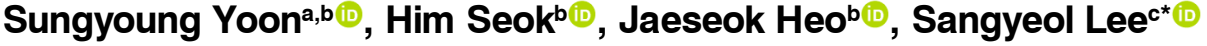

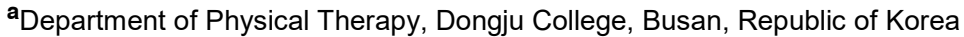 \\ bepartment of Physical Therapy, Kyungsung University Graduate School Busan, Republic of Korea \\ 'Department of Physical Therapy, Kyungsung University, Busan, Republic of Korea
}

\begin{abstract}
Objective: The purpose of this study was to investigate the effect of 3-dimensional posture correction(3DPC) exercise program incorporating PNF respiratory muscle strengthening(RMS) exercise on spinal alignment and trunk expansion in patients with idiopathic scoliosis and the difference in intervention effect by type of idiopathic scoliosis.
\end{abstract}

Design: Comparative study using paired t-test and analysis of variance measures.

Methods: The subjects of this study were 5 men and 24 women diagnosed with idiopathic scoliosis with a Cobb angle greater than 10 degrees and less than 45 degrees. A 3DPC exercise program incorporating PNF RMS exercise was conducted twice a week for 1 hour per session for 6 weeks, and Cobb angle, Angle of trunk rotation, and trunk expansion were measured before and after the intervention.

Results: After the intervention, Cobb angle and trunk rotation angle showed a statistically significant decrease, and trunk expansion showed a statistically significant increase. In the effect difference by type, there was a statistically significant difference in the angle of trunk rotation of the thoracic in $3 \mathrm{C}$ and Single Lumbar.

Conclusions: In conclusion, it is thought that a 3DPC exercise program incorporating PNF RMS exercise can be effectively used in clinical practice to improve spinal alignment and trunk expansion in patients with idiopathic scoliosis.

Key Words: Idiopathic scoliosis, Spinal alignment, Trunk expansion, PNF

서론

우리나라의 2016년 통계청자료에 따르면 척추측만증 환자는 총 11 만 3000 명으로 조사되었으며 연령층이 낮아 질수록 높은 비율을 차지하며 (10대 $44.4 \%, 20$ 대 $15.9 \%$, 30 대 $8.8 \%, 40$ 대 $6.8 \%, 50$ 대 $6.7 \%, 60$ 대 $5.3 \%, 90$ 대 $5.1 \%)$ 척추측만증을 치료하기 위해 연간 지출되는 비용 은 총 185 억으로 조사되었다.

척추측만증이란 관상면상에서 척추의 2차원적 외측만 곡(lateral curvature)변형과 추체(vertebral body)의 회전 (rotation)이 복합되어 시상면 및 횡단면상의 변형이 동
시에 발생되는 3 차원적인 변형이다[1]. 세계척추측만증 연구회(scoliosis research society, SRS)에 따르면 척추 측만증은 영상의학적으로 척추뼈가 회전과 함께 측면으 로 이동하여 콥 각도(Cobb angle)가 $10^{\circ}$ 이상일 때를 말한다[2]. 특발성 척추측만증은 구조적 측만증의 하나 로 전체 비율에 80 85\%를 차지한다[3]. 특발성 척추측 만증의 경우 정확하게 직접적인 원인이 아직까지 밝혀 지지 않았으며 척추의 3 차원적인 변형은 시간이 지남에 따라 허리, 심폐, 주변장기의 통증과 기능장애를 일으킨 다[4].

척추측만증의 치료방법으로는 물리치료나 보조기 착용

Received: Oct 27, 2021 Revised: Dec 6, 2021 Accepted: Dec 8, 2021

Corresponding author: Sangyeol Lee (ORCID https://orcid.org/0000-0003-4428-9101)

Department of Physical Therapy, Kyungsung University, Busan Nam-gu Suyeong-ro 309, kyungsung University Hall No. 12401 Republic of Korea Tel: +82-10-5037-0787 E-mail: sjslh486@ks.ac.kr

This is an Open-Access article distributed under the terms of the Creative Commons Attribution Non-Commercial License (http://creativecommons.org/licenses/ by-nc/4.0) which permits unrestricted non-commercial use, distribution, and reproduction in any medium, provided the original work is properly cited. Copyright @ 2021 Korean Academy of Physical Therapy Rehabilitation Science 
등과 같은 보존적 방법과 수술적 방법이 있다[5]. 세계척 추측만증연구회에서는 척추측만증 개선을 위해 물리치료 와 보조기를 모두 적용할 것을 권장하고 있다[6]. 현재 척 추측만증의 물리치료 중재방법은 아주 다양하게 있으며 대부분의 치료의 기본원리에는 3 차원적인 접근이 있으며 [7], Dubousset[8]는 척추측만증의 중재 시 3차원적으로 접근하는 것이 중요하다고 하였다.

척추측만증의 중재 중 하나인 Schroth에서는 회전호흡 (rotational angular breathing)이라는 호흡법을 이용하여 뒤틀린 부위의 근육강화와 갈비뼈를 이용하여 척추의 위 치를 회복시키는 3 차원적 운동을 실행하고 있으며[9], 또 다른 중재 방법인 BSPTS(Barcelona Scoliosis Physical Therapy School)에서도 회전호흡법을 이용하여 3차원적 인 치료접근을 하고 있다[7]. 또한 Negrini 등[10]과 Otman 등[11]의 연구에서 Schroth와 같은 척추측만증의 3 차원적 운동중재 방법이 콥 각도(Cobb angle)의 개선과 폐활량, 근력 및 자세교정에 긍정적인 영향을 미친다고 보 고하였다.

고유수용성신경근촉진법(proprioceptive neuromuscular facilitation, PNF)은 Herman Kabat과 Margaret Knott에 의해 시작된 신경생리학적 치료로써 근육과 관절 안의 고 유수용성감각의 자극을 통해 신경근의 움직임을 증진시키 기 위해 고안된 운동 방법이며[12], PNF를 이용한 호흡 운동은 가슴우리의 가동범위를 증진시키기 위한 목적으로 하는 운동방법이라고 하였다[13]. 호흡근 강화 운동은 가 동범위를 통한 신장방법을 지속적으로 사용하여 흡기량의 증가를 통한 몸통의 운동성을 증가시키며 간접적인 적응 증으로는 가슴부분의 가동성, 몸통과 어깨부분의 가동성, 경련성 감소, 통증완화가 있다. 또한 저항성 근력운동을 실시하여 가슴부분의 운동을 유도하며 등장성 운동을 결 합하는 것이 호흡운동 조절과 호흡근의 강화를 위해 효과 적인 방법이다[13].

이전의 여러 연구에서 $\mathrm{PNF}$ 를 이용한 척추측만증의 치 료중재와 관련된 많은 연구들이 있었다. $\mathrm{Na}$ 와 $\mathrm{Shin}[14]$ 은 $\mathrm{PNF}$ 패턴과 테크닉이 성인 척추측만증 환자의 콥 각도와 허리엉치뼈의 능동운동범위 및 일상생활에 영향을 미친다고 하였으며 Stepien 등[15]은 일측성 고유수용성신경근촉진 법 가동술(Unilateral PNF Mobilization)은 척추측만증의 몸통 회전각도의 감소와 운동 범위를 개선한다고 보고하였 으며 Stepien 등[15]은 PNF의 수축-이완(Contract-Relax) 기법과 비대칭 호흡과 함께 사용되는 PNF 양측 다리 패 턴은 척추측만증 소녀의 몸통 회전각도 및 몸통과 골반회 전에 영향을 미친다고 하였다. 앞선 여러 선행연구에서 PNF 패턴 및 테크닉을 척추측만증의 치료중재방법으로 사용한 연구는 많았지만 척추측만증의 3차원적인 치료접 근에 $\mathrm{PNF}$ 의 호흡근 강화 운동을 접목하여 척추측만증의
중재효과를 알아보는 연구는 아직 이루어진 바 없었다.

따라서 본연구는 PNF 호흡근 강화 운동을 접목한 3 차 원적 자세교정 운동프로그램을 적용한 6 주간의 특발성 척 추측만증 치료중재가 척추정렬과 몸통확장에 미치는 영향 과 특발성 척추측만증 환자의 유형별로 중재의 효과 차이 를 알아보고자 한다.

\section{연구 방법}

연구 대상

본 연구는 의료기관에서 콥 각도가 10 도 이상 45 도 미 만으로 척추뼈 몸통의 회전을 동반한 특발성 척추측만증 진단을 받고 부산 소재 $\mathrm{OO}$ 운동센터에 방문하고 있는 29 명(여성 24명, 남성 5명)을 대상으로 연구의 전체적인 실 험 과정 및 방법과 목적에 대한 충분한 설명을 들은 후 연구 윤리를 준수하여 자발적인 동의 하에 실험을 진행하 였다. 근육의 불균형 및 통증으로 인한 기능적 척추측만 증, 신경근의 변이 또는 척추뼈 몸통의 변형으로 인한 선 천성 척추측만증, 최근 상, 하지 및 허리에 신경학적, 정 형외과적 질환이 있거나 척추 수술의 병력, 다리 길이 차 이가 있는 대상자는 연구에서 제외하였다. 대상자의 기본 적인 정보를 분석하기 위해 연령, 신장, 체중, 체질량지수 (BMI)를 포함한 특성을 조사하였다.

\section{평가 방법 및 측정 도구}

\section{콥 각도(Cobb Angle)}

방사선 검사를 통해 척추뼈의 변화를 객관화할 수 있는 콥 각도를 측정하였다. 부산시 소재 의료기관에서 촬영하 였으며, 촬영을 시작하기 전에 주의점을 설명한 후 선 자 세로 진행하였다. 콥 각도는 등뼈와 허리뼈를 나누어 오 목한 방향으로 척추뼈의 윗면이 가장 많이 기울어진 상부 척추뼈와 아랫면이 가장 많이 기울어진 하부 척추뼈를 결 정한 후, 상부 끝 척추뼈의 상단과 하부 끝 척추뼈의 하단 에 선을 그은 후 두개의 선이 교차한 각을 측정하였다 [16-19].

\section{몸통 회전각(Angle of trunk rotation)}

척추측만증으로 인한 몸통의 회전각을 측정하기 위해 앞 굽힘 검사를 실시하였다. 앞 굽힘 검사에서 나타나는 갈비뼈 봉우리 징후를 측정하기 위해 척추측만계(Scoliometer, Orthopedic systems, USA)를 이용하였다[20, 21]. 척추 측만계의 움푹 팬 부분이 대상자의 가시돌기에 위치하여, 등뼈 구획과 허리뼈 구획에서 기울기가 가장 큰 곳을 측 정하였다[22]. 


\section{몸통 확장성(Trunk expansion)}

중재 전후에 몸통의 확장성을 비교하기 위하여 겨드랑 이 부위, 칼돌기부위, 허리 부위를 측정하였다[23, 24]. 겨 드랑이 부위는 양팔을 벌리고 겨드랑이에 줄자를 수평으 로 놓고 몸통에 붙여서 측정하였고 칼돌기 부위는 칼돌기 바로 위에 줄자를 수평으로 지나도록 하여 측정하였다.허 리 부위는 가장 많이 굽이가 들어간 지점에서 측정하였다. 세측정부위에서 안정 시 상태와 최대 흡기 시에 각각의 측정을 3 회 반복측정 후 평균값을 측정값 $(\mathrm{cm})$ 으로 기록하 였다.

\section{연구 절차}

3 차원적 자세교정 운동프로그램은 준비 운동, 본 운동, 마무리 운동으로 구성하였다. 운동프로그램은 주 2 회 운 동센터를 방문하여 회당 1 시간씩 6주간 실시하였다. 준비 운동은 골반 교정(pelvic correction)과 매달리기(semi -hanging)를 10 분간 실시하였다.

본 운동 시 BSPTS의 교정 요소에 따라 자가 신장, 역휨 (deflection), 역회전(derotation), 회전호흡(rotational angular breathing), 안정화(stabilization)를 포함하였으며 척추측 만증으로 인해 변형된 가슴우리의 움직임과 확장을 증가 시키기 위하여 PNF 호흡근 강화운동을 진행하였다[13, $25,26]$ (Table 1). 첫번째 운동은 옆으로 누운자세에서 가로막 촉진을 유도하기 위해 치료사 손바닥 안쪽의 새끼 두덩(hypothenar eminence)을 대상자의 배꼽에 두고서 대상자가 날숨 시 가슴우리 아래에서부터 위 방향으로 압 박을 가하였다. 날숨의 마지막 단계에서 치료사는 아래팔 과 손을 뒤침(supination)하면서 새끼두덩을 이용하여 가 로막을 머리 방향으로 재빠른 신장(Quick stretch)을 적 용하였다. 가로막 수축을 통한 들숨의 시작을 유도하기 위해 신장 반사(stretch reflex)를 이용하였다. 치료사는 대상자가 들숨을 하는 동안 아래팔과 손을 엎침 (pronation)하면서 가로막이 아래방향으로 수축할 수 있 도록 유도하였다. 등장성 수축의 혼합기법(combination of isotonic)을 결합하여 들숨과 날숨을 10 회씩 5 세트 시 행하였다(Figure 1).

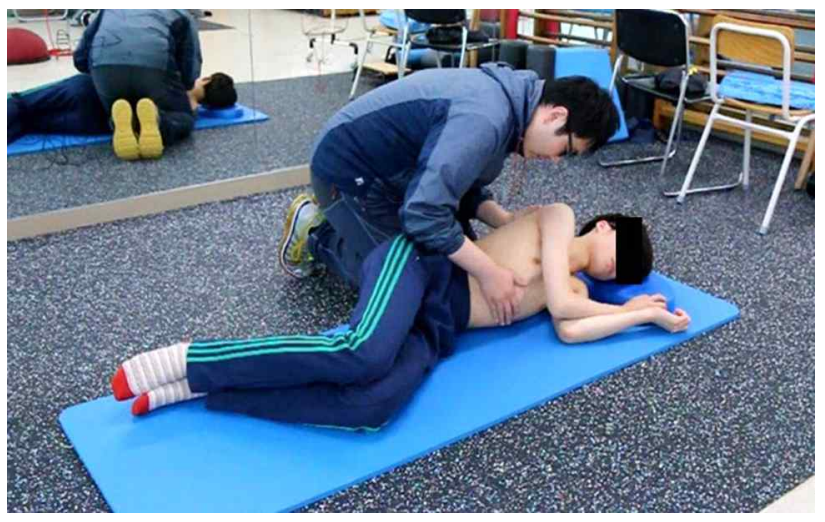

Figure 1. PNF respiratory muscle strengthening exercise in side-lying

두번째 운동은 무릎을 세워 바로 누운 자세에서 첫번째 운동 방법과 같게 시행하였다. 옆으로 누운 자세 보다 중 력의 영향을 많이 받기에 가로막 수축이 제대로 일어나지 않을 경우 다시 첫번째 운동으로 돌아가 옆으로 누운 자 세에서 충분한 수축을 익히고 시행하였다. 가로막 수축을 촉진하기 위해 등장성 수축의 혼합기법을 결합하여 들숨 과 날숨을 10 회씩 5 세트 시행하였다.

세번째 운동은 무릎을 세워 바로 누운 자세에서 가로 막과 갈비사이근 촉진을 유도하기 위해 치료사의 양손 으로 아래쪽 갈비뼈 위에 두고서 대상자가 날숨시 꼬리 쪽과 안쪽으로 비스듬하게 압력을 가한다. 날숨의 마지 막 단계에서 치료사는 재빠른 신장을 적용하여 가로막 수축을 유도하였다. 척추측만증으로 인해 변형된 가슴 벽의 움직임을 대칭적으로 하기 위해 강조 타이밍 (timing for emphasis)를 활용하였다. 좀 더 강하고 더 움직임이 많은 배측 갈비뼈 봉우리(ventral rib hump) 의 움직임을 방지하고 약화된 배측 평면구간(ventral flat zone)을 촉진시키고자 등장성 수축의 혼합기법과 반복신장을 들숨과 날숨 호흡 운동을 10 회씩 5 세트 시 행하였다(Figure 2).

Table 1. PNF respiratory muscle strengthening exercise

\begin{tabular}{lllll}
\hline Item & Position & Purpose & Basic principles & Technique \\
\hline 1 & Side lying & Facilitate Diaphragm Movement & VC, MC, Resistance, Stretch & CI, RS \\
\hline 2 & Supine & Facilitate Diaphragm Movement & VC, MC, Resistance, Stretch & CI, RS \\
\hline 3 & Supine & $\begin{array}{l}\text { Facilitate Diaphragm Movement } \\
\text { Chest mobilization }\end{array}$ & VC, MC, Resistance, Stretch Timing for & CI, RS \\
& & Emphasis & \\
\hline
\end{tabular}

VC: verbal commend; MC: manual contact; $\mathrm{CI}$ : combination of isotonic; RS: repeated stretch 


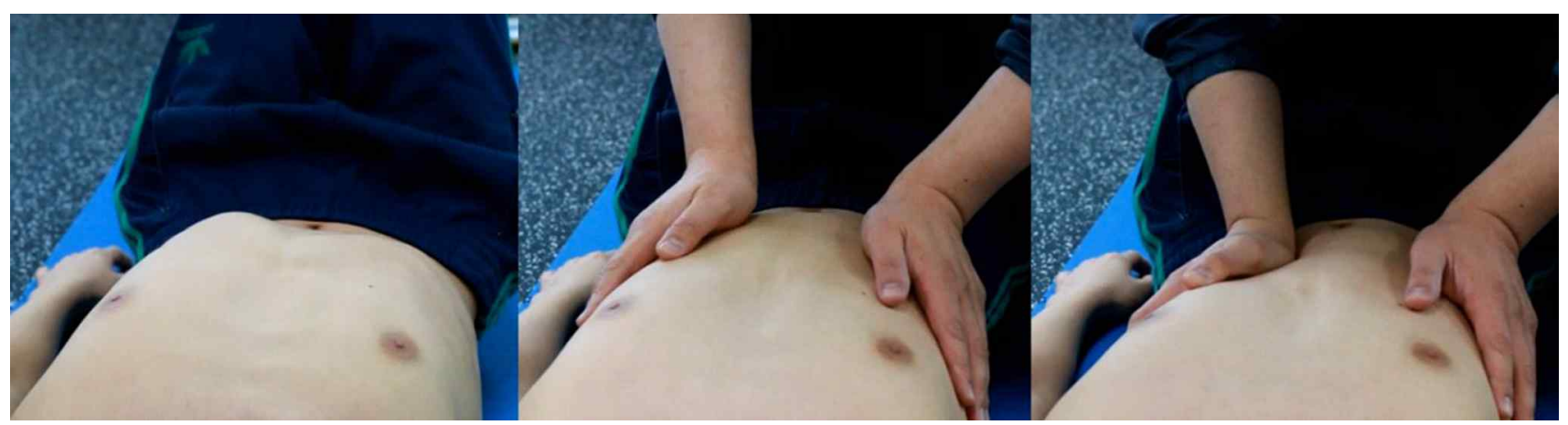

Figure 2. PNF respiratory muscle strengthening(RMS) exercise in supine

마무리 운동은 10 분간 실시하였다. 본 운동 이후 앉았 다가 서서 이동하기, 불안정한 지면에 서기 등 과제지향 적 운동을 통해 스스로 교정된 자세를 유지하도록 하였 다. 과도한 구부림 동작과 회전 운동은 금지하였으며 운 동 시 통증이나 어지럼증이 나타나면 운동을 즉시 중단하 였다.

\section{자료 분석}

본 연구는 실험을 통해 수집된 자료를 SPSS 25 통계 프로그램을 이용하여 통계처리 하였다. 기술통계를 통해 대상자의 일반적인 특성을 평균과 표준편차로 산출하였으 며, 특발성 척추측만증 그룹의 중재 전후의 차이를 검증 하기 위해서 대응표본 $\mathrm{t}$-검정을 실시하였다. 그리고 특발 성 척추측만증 환자의 유형별 그룹 간 중재 적용 이후 차 이를 비교하기 위하여 일원배치 분산분석(One-way ANOVA)을 실시하였으며, 추가적으로 Bonferroni 사후 분석을 실시하였다. 모든 통계처리를 위한 유의수준은 0.05 로 설정하였다.

\section{연구 결과}

\section{연구 대상지들의 일반적인 특성}

참여 대상자는 남자 5명, 여자 24명으로 총 29명이며, 평균 연령 $20.44 \pm 6.42$ 세, 평균 신장은 $163.53 \pm 6.84 \mathrm{~cm}$, 평균 체중은 $50.13 \pm 8.82 \mathrm{~kg}$, 신체질량지수는 $18.83 \pm 2.32$ $\mathrm{kg} / \mathrm{m}^{2}$ 이었다.

6주간 PNF 호흡근 강화 운동을 접목한 3차원적 자세교정 운동프로그램 중재 전후의 콥 각도, 몸통 회전각, 몸통 확장 비교

6주간 PNF의 호흡근 강화 운동 전후 콥 각도, 몸통 회 전각, 몸통 확장의 변화를 알아보기 위해 대응표본 $\mathrm{t}$ 검정
을 실시하였다. 중재 전의 경우 콥 각도가 등뼈에서는 $34.86 \pm 12.94$, 중재 후에는 $29.53 \pm 11.56$ 로 유의하게 감소 하였다 $(\mathrm{p}<.05)$. 중재 전의 콥 각도가 허리뼈에서는 30.31 \pm 11.27 , 중재 후에는 $25.44 \pm 9.92$ 로 유의하게 감소하였다 $(\mathrm{p}<.05)$. 몸통 회전각이 등뼈에서는 중재 전 $8.03 \pm 4.47$, 중재 후에는 $4.86 \pm 3.34$ 로 유의하게 감소하였다 $(\mathrm{p}<.05)$. 몸통 회전각이 허리뼈에서는 중재 전 $7.89 \pm 4.45$, 중재 후 에는 $3.70 \pm 3.15$ 로 유의하게 감소하였다 $(\mathrm{p}<.05)$. 몸통 확 장이 겨드랑이 부분에서는 중재 전 $82.00 \pm 5.92$, 중재 후 에는 $82.41 \pm 5.89$ 로 유의하게 증가하였다 $(\mathrm{p}<.05)$. 칼돌기 부분에서는 중재 전 $73.86 \pm 6.46$, 중재 후에는 $74.63 \pm 6.43$ 로 유의하게 증가하였다 $(\mathrm{p}<.05)$. 허리 부분에서는 중재 전 $66.05 \pm 6.13$, 중재 후에는 $68.01 \pm 6.16$ 로 유의하게 증가 하였다 $(\mathrm{p}<.05)($ Table 2$)$.

6주간 PNF 호흡근 강화 운동을 접목한 3차원적 자세교정 운동프로그램 중재 후 특발성 척추측만증 환자의 유형별 그룹 콥 각도, 몸통 회전각, 몸통 확장 비교

6주간 PNF 호흡근 강화 운동을 접목한 3차원적 자세 교정 운동프로그램 중재 전후 특발성 척추측만증 환자의 유형별 그룹 간의 비교를 위해 일원배치 분산분석을 실시 하였다. 콥 각도가 등뼈는 $3 \mathrm{C}$ 일 경우 $-4.75 \pm 1.75,4 \mathrm{C}$ 일 경우 $-6.12 \pm 3.60$, Single Lumbar일 경우 $-2.92 \pm 0.60$, $\mathrm{N} 3 \mathrm{~N} 4$ Group의 경우 $-7.83 \pm 5.03$ 였으며, 통계학적으로 유 의한 차이가 없었다 $(\mathrm{p}>0.05)($ Table 3$)$.

콥 각도가 허리뼈는 $3 \mathrm{C}$ 일 경우 $-3.87 \pm 1.95,4 \mathrm{C}$ 일 경우 $-6.75 \pm 3.41$, Single Lumbar일 경우 $-4.71 \pm 1.70$, N3N4일 경우 $-3.83 \pm 4.79$ 였으며, 통계학적으로 유의한 차이가 없 었다 $(\mathrm{p}>0.05)($ Table 3$)$.

몸통 회전각이 등뼈에서 $3 \mathrm{C}$ 일 경우 $-4.18 \pm 2.17,4 \mathrm{C}$ 일 경우 $-3.25 \pm 1.28$, Single Lumbar일 경우 $-1.50 \pm 1.11$, $\mathrm{N} 3 \mathrm{~N} 4$ 일 경우 $-3.66 \pm 1.03$ 였으며, 통계학적으로 유의한 차 이가 있었다 $(\mathrm{p}<0.05)$. 중재 후 그룹 간의 비교를 위한 
Table 2. Comparison of parameters before and after Intervention of 3DPC exercise incorporating PNF RMS exercise

\begin{tabular}{llllll}
\hline Variable & & Pre-Test & Post-Test & t & p \\
\hline \multirow{2}{*}{ Cobb angle } & Thoracic & $34.86 \pm 12.94^{\mathrm{a}}$ & $29.53 \pm 11.56$ & 8.39 & $0.000^{*}$ \\
\cline { 2 - 6 } & Lumbar & $30.31 \pm 11.27$ & $25.44 \pm 9.92$ & 8.22 & $0.000^{*}$ \\
\hline \multirow{2}{*}{ ATR } & Thoracic & $8.03 \pm 4.47$ & $4.86 \pm 3.34$ & 9.71 & $0.000^{*}$ \\
\cline { 2 - 7 } & Lumbar & $7.89 \pm 4.45$ & $3.70 \pm 3.15$ & 8.94 & $0.000^{*}$ \\
\hline \multirow{2}{*}{ TE } & Axilla & $82.00 \pm 5.92$ & $82.41 \pm 5.89$ & -4.16 & $0.000^{*}$ \\
\cline { 2 - 7 } & Xyphoid & $73.86 \pm 6.46$ & $74.63 \pm 6.43$ & -10.09 & $0.000^{*}$ \\
\cline { 2 - 7 } & Waist & $66.05 \pm 6.13$ & $68.01 \pm 6.16$ & -12.38 & $0.000^{*}$ \\
\hline
\end{tabular}

${ }^{\mathrm{a}}$ Mean $\pm \mathrm{SD},{ }^{*} \mathrm{p}<0.05$, ATR: angle of trunk rotation, TE: trunk expansion, 3DPC: 3D postural correction, RMS: respiratory muscle strengthening

Table 3. Comparison of group by type of Idiopathic scoliosis patient after Intervention of 3DPC exercise incorporating PNF RMS exercise

\begin{tabular}{|c|c|c|c|c|c|c|c|}
\hline Variable & & $\begin{array}{l}3 C \\
(n=8)\end{array}$ & $\begin{array}{l}4 C \\
(n=8)\end{array}$ & $\begin{array}{l}\text { Single Lumbar } \\
(n=7)\end{array}$ & $\begin{array}{l}\text { N3N4 } \\
(n=6)\end{array}$ & $\mathbf{F}$ & $\mathbf{p}$ \\
\hline \multirow{2}{*}{ Cobb angle } & Thoracic & $-4.75 \pm 1.75^{\mathrm{a}}$ & $-6.12 \pm 3.60$ & $-2.92 \pm 0.60$ & $-7.83 \pm 5.03$ & 2.95 & 0.052 \\
\hline & Lumbar & $-3.87 \pm 1.95$ & $-6.75 \pm 3.41$ & $-4.71 \pm 1.70$ & $-3.83 \pm 4.79$ & 1.48 & 0.243 \\
\hline \multirow{2}{*}{ ATR } & Thoracic & $-4.18 \pm 2.17$ & $-3.25 \pm 1.28$ & $-1.50 \pm 1.11$ & $-3.66 \pm 1.03$ & 4.26 & $0.015^{*}$ \\
\hline & Lumbar & $-2.25 \pm 1.16$ & $-5.25 \pm 2.49$ & $-4.78 \pm 1.07$ & $-4.66 \pm 3.88$ & 2.64 & 0.071 \\
\hline \multirow{3}{*}{$\mathrm{TE}$} & Axilla & $0.50 \pm 0.37$ & $0.50 \pm 0.53$ & $0.42 \pm 0.73$ & $0.16 \pm 0.51$ & 0.53 & 0.661 \\
\hline & Xyphoid & $0.87 \pm 0.44$ & $0.93 \pm 0.17$ & $0.64 \pm 0.37$ & $0.58 \pm 0.58$ & 1.27 & 0.306 \\
\hline & Waist & $1.56 \pm 0.62$ & $2.06 \pm 0.82$ & $2.57 \pm 0.83$ & $1.66 \pm 0.93$ & 2.33 & 0.098 \\
\hline
\end{tabular}

${ }^{\mathrm{a}}$ Mean $\pm \mathrm{SD},{ }^{*} \mathrm{p}<0.05$, ATR: angle of trunk rotation, TE: trunk expansion, 3DPC: 3D postural correction, RMS: respiratory muscle strengthening, $3 \mathrm{C}$ : three curves, $4 \mathrm{C}$ : four curves, N3N4: non three-non four

Bonferroni 사후검정에서 3C와 Single Lumbar 간에 통 계학적으로 유의한 차이가 나타났으며 $(\mathrm{p}<0.05)$, 나머지 그룹에서는 통계학적으로 유의한 차이가 없었다 $(\mathrm{p}>0.05)$ (Table 3). 몸통 회전각이 허리뼈는 $3 \mathrm{C}$ 일 경우 $-2.25 \pm 1.16$, $4 \mathrm{C}$ 일 경우 $-5.25 \pm 2.49$, Single Lumbar일 경우 $-4.78 \pm 1.07$, $\mathrm{N} 3 \mathrm{~N} 4$ 일 경우 $-4.66 \pm 3.88$ 였으며, 통계학적으로 유의한 차 이가 없었다 $(\mathrm{p}>0.05)($ Table 3$)$.

몸통 확장은 겨드랑이 부분이 $3 \mathrm{C}$ 일 경우 $0.50 \pm 0.37$, $4 \mathrm{C}$ 일 경우 $0.50 \pm 0.53$, Single Lumbar일 경우 $0.42 \pm 0.73$, $\mathrm{N} 3 \mathrm{~N} 4$ 일 경우 $0.16 \pm 0.51$ 였으며, 통계학적으로 유의한 차 이가 없었다 $(\mathrm{p}>0.05)($ Table 3$)$. 몸통 확장은 칼돌기 부분 이 $3 \mathrm{C}$ 일 경우 $0.87 \pm 0.44,4 \mathrm{C}$ 일 경우 $0.93 \pm 0.17$, Single Lumbar일 경우 $0.64 \pm 0.37, \mathrm{~N} 3 \mathrm{~N} 4$ 일 경우 $0.58 \pm 0.58$ 였으 며, 통계학적으로 유의한 차이가 없었다 $(\mathrm{p}>0.05)(\mathrm{Table}$ $3)$. 몸통 확장은 허리 부분이 $3 \mathrm{C}$ 일 경우 $1.56 \pm 0.62,4 \mathrm{C}$ 일 경우 2.06 \pm 0.82 , Single Lumbar일 경우 $2.57 \pm 0.83$,
$\mathrm{N} 3 \mathrm{~N} 4$ 일 경우 $1.66 \pm 0.93$ 였으며, 통계학적으로 유의한 차 이가 없었다 $(\mathrm{p}>0.05)($ Table 3$)$.

\section{고찰}

척추측만증은 척추와 몸통의 3 차원적인 변형으로 시간 이 지남에 따라 가슴우리의 팽창이 제한되고 가로막 움직 임의 불균형을 초래한다. 척추측만증 환자는 매년 증가하 면서 사회적 문제점으로 부각되고 있다. 사춘기에 발생하 여 성장과 함께 콥 각도도 증가하며, 계속 진행 시에는 심 장과 폐의 기능에 장애를 유발하는 위험성이 있다[26]. 척 추측만증으로 인하여 뒤틀어진 가슴우리에는 폐 공간 역 시 뒤틀어져 있으며 이러한 상태에서의 일반적인 호흡은 흡기 시 갈비벼의 돌림을 더욱 증가시켜 폐기능의 저하가 나타난다고 하였다[27]. 이에 따라 본 연구는 특발성 척추 측만증 환자를 대상으로 6주간의 PNF 호흡근 강화 운동 
을 접목한 3 차원적 자세교정 운동프로그램이 몸통확장과 척추정렬에 미치는 영향과 특발성 척추측만증 환자의 유 형별 그룹 간 중재의 효과 차이를 알아보고자 하였다.

특발성 척추측만증 환자를 대상으로 6 주간의 호흡근 강화 운동 전후를 비교하였을 때 콥 각도, 몸통 회전각, 몸통 확장에 유의한 차이가 있었다 $(\mathrm{p}<0.05)$. Asher와 Burton[28]의 연구에서는 특발성 척추측만증은시상면의 정상적인 정렬상태가 소실되며 관상면상에서의 변형이 나 타나게 된다. 회전호흡은 몸통의 형상 및 호흡능력을 개 선시키는 운동방법으로 좁아진 갈비사이를 늘려주고 가로 막과 호흡근육의 정상화를 도모하며 불균형된 자세의 향 상과 척추측만증의 만곡을 감소시킬 수 있다[29, 30]. 이 러한 호흡운동은 콥 각도의 감소에 도움을 주는 중요한 요인이 된다 $[10,24,31]$. 다른 선행연구에서는 신경운동 조절과 척추의 안정성, 호흡기능 및 자세의 균형능력을 향상시킨다고 보고하였다[32-35].

본 연구에서는 3차원적 자세교정 운동프로그램에 $\mathrm{PNF}$ 호흡근 강화 운동을 접목하여 6주간 중재하였다. $\mathrm{PNF}$ 를 사용한 호흡운동은 가슴우리의 가동범위를 증진시키는 목 적으로 하는 운동방법이라고 하였다[13]. PNF는 10가지 의 기본 원리 및 절차를 가지고 있으며 그 중 하나인 타 이밍은 정상적인 타이밍(Nomal timing)과 강조를 위한 타이밍으로 구분된다. 정상적인 타이밍은 신체움직임의 정상적인 순서를 촉진시키기 위한 방법이며, 강조를 위한 타이밍은 정상적인 운동순서를 변형시켜 원하는 분절의 활동을 촉진시키기 위해 쓰는 방법이다[13]. PNF의 호흡 운동에서 강조를 위한 타이밍을 사용하였을 경우 좀더 강 하고 좀더 움직임이 많은 측에서의 움직임을 방지함으로 약화된 쪽 또는 제한된 쪽의 움직임을 촉진시킬 수 있을 것이라고 하였다[13]. 이러한 선행연구를 바탕으로 PNF 호흡근 강화 운동을 접목한 3 차원적 자세교정 운동프로그 램은 척추측만증 환자의 척추정렬과 몸통확장에 영향을 미쳤을 것으로 사료된다. 특히 척추측만증 환자의 가슴우 리에서 좀더 움직임이 많아 주로 호흡을 하는 부분과 움 직임이 제한되어 호흡이 되지 않는 부분을 볼 수 있는데 $\mathrm{PNF}$ 호흡근 강화 운동에서 강조를 위한 타이밍이 호흡이 되지 않은 부분을 활성화시켰을 것으로 생각된다.

본 연구에서는 중재 후 특발성 척추측만증의 유형별 그 룹 간에서는 통계적으로 유의한 차이가 나타나지 않았으 나, 몸통 회전각이 등뼈부분에서만 사후분석에서 $3 \mathrm{C}$ 와 Single Lumbar에서 유의한 차이를 보였다. Rigo 등[17] 은 수술에 초점이 맞춰져 있으며 보존적인 치료 방법과 연관이 없는 기존의 분류에 대한 한계를 극복하고자 Katharina Schroth가 고안한 Schroth 분류를 바탕으로 변 형된 몸통을 3 차원적으로 구획화하였다. 등뼈에 주된 굽 이가 있으며, 허리뼈를 포함하지 않거나 허리뼈 또는 등
허리뼈 굽이를 포함하고 있는 $3 \mathrm{C}, 4 \mathrm{C}$, Non3-Non4 $(\mathrm{N} 3 \mathrm{~N} 4)$ 유형과 허리뼈 또는 등허리뼈 굽이와 직선의 등 뼈가 있는 Single Lumbar(Thoracolumbar) 유형이 있다. 3C, 4C, N3N4 유형과 Single Lumbar(Thoracolumbar) 유형은 등뼈 굽이의 유무로 차이가 나타난다. 특히 $3 \mathrm{C}$ 유 형과 Single Lumbar(Thoracolumbar) 유형의 유의한 차 이점이 나타나는 이유는 $3 \mathrm{C}$ 의 경우 등뼈 굽이가 크기 때 문에 중재의 영향을 가장 많이 받았을 것이고 Single Lumbar의 경우 등뼈 굽이가 없기에 중재의 영향을 가장 적게 받을 것으로 사료된다. $4 \mathrm{C}$ 유형과 $\mathrm{N} 3 \mathrm{~N} 4$ 유형의 경 우 등뼈 굽이와 허리 굽이가 적절하게 보상하고 있기에 Single Lumbar 유형과 유의한 차이점을 보이고 있지 않 는 것으로 사료된다.

몸통 회전각의 등뼈부분을 제외한 나머지 결과에서는 유의한 차이가 나타나지 않았다. 이러한 결과는 모든 유 형의 특발성 척추측만증 환자에게 동일한 효과를 제공하 였을 것으로 사료되며, 또한 본 연구의 운동프로그램이 척추의 유형에 영향을 받지 않고 모든 유형에 적용 시 개 선에 긍정적인 영향을 미칠 것으로 사료된다.

본 연구의 제한점으로는 대조군을 설정하지 않았으며, 그로 인해 실질적인 PNF 호흡근 강화 운동을 접목한 3차 원적 자세교정 운동프로그램의 독립적인 효과를 입증하는 데 다소 한계가 있을 것으로 판단된다. 추후 연구에서는 대조군의 설정과 더 많은 수의 대상자들의 모집을 통해 $\mathrm{PNF}$ 호흡근 강화 운동을 접목한 3 차원적 자세교정 운동 프로그램 적용에 따른 척추측만증 환자의 척추측만의 각 도와 관련된 기능적 요소들에 대한 후속연구가 필요하다 고 생각된다.

\section{결론}

본 연구는 특발성 척추측만증 환자에게 PNF 호흡근 강화 운동을 접목한 3 차원적 자세교정 운동프로그램 적용 이 척추정렬과 몸통확장에 미치는 효과를 연구하였고, $\mathrm{PNF}$ 호흡근 강화 운동을 접목한 3차원적 자세교정 운동 프로그램 적용이 이를 효과적으로 개선하는 것을 증명하 였다. 더 나아가 본 연구 결과가 특발성 척추측만증 환자 의 척추정렬과 몸통확장 개선을 위한 임상적인 기초자료 로 활용 될 것으로 사료된다.

\section{참고문헌}

1. Weinstein SL, Dolan LA, Cheng JC, Danielsson A, Morcuende JA. Adolescent idiopathic scoliosis. The lancet. 2008;371:1527-37.

2. Negrini S, Hresko TM, O’brien JP, Price N, Committee 
SN-O. Recommendations for research studies on treatment of idiopathic scoliosis: Consensus 2014 between SOSORT and SRS non-operative management committee. Scoliosis. 2015;10:8.

3. Negrini S, Donzelli S, Aulisa AG, Czaprowski D, Schreiber S, de Mauroy JC, et al. 2016 SOSORT guidelines: orthopaedic and rehabilitation treatment of idiopathic scoliosis during growth. Scoliosis Spinal Disord. 2018;13:3.

4. Trobisch P, Suess O, Schwab F. Idiopathic scoliosis. Dtsch. Ärztebl. int. 2010;107:875.

5. Lee J-H, Kim S-Y. Comparative effectiveness of Schroth therapeutic exercise versus sling therapeutic exercise in flexibility, balance, spine angle and chest expansion in patient with scoliosis. Korean Soc phys med. 2014;9:11-23.

6. Marti CL, Glassman SD, Knott PT, Carreon LY, Hresko MT. Scoliosis Research Society members attitudes towards physical therapy and physiotherapeutic scoliosis specific exercises for adolescent idiopathic scoliosis. Scoliosis. 2015;10:1-7.

7. Bettany-Saltikov J, Cook T, Rigo M, De Mauroy J, Romano M, Negrini S, et al. Physical therapy for adolescents with idiopathic scoliosis: IntechOpen; 2012.

8. Dubousset $\mathrm{J}$, Importance of the three-dimensional concept in the treatment of scoliotic deformities. International Symposium on 3D Scoliotic deformities joined with the VIIth International Symposium on Spinal Deformity and Surface Topography; 1992.

9. Lehnert-Schroth C. Introduction to the three-dimensional scoliosis treatment according to Schroth. Physiotherapy. 1992;78:810-5.

10. Negrini S, Atanasio S, Zaina F, Romano M. Rehabilitation of adolescent idiopathic scoliosis: results of exercises and bracing from a series of clinical studies: Europa Medicophysica-SIMFER 2007 Award Winner. 2008.

11. Otman S, Kose N, Yakut Y. The efficacy of Schroth's 3-dimensional exercise therapy in the treatment of adolescent idiopathic scoliosis in Turkey. Neurosci. J. 2005;10:277-83.

12. Kofotolis N, Vrabas I, Vamvakoudis E, Papanikolaou A, Mandroukas K. Proprioceptive neuromuscular facilitation training induced alterations in muscle fibre type and cross sectional area. Br. J. Sports Med. 2005;39:e11-e.

13. Adler SS, Beckers D, Buck M. PNF in practice: an illustrated guide: Springer; 2007.

14. Na E-J, Shin S-S. The Effects of PNF on Active Lumbar Flexion ROM and Activity of Daily Living for Adult Scoliosis with Low Back Pain. PNF and Movement. 2012;10:33-40.

15. Stępień A, Fabian K, Graff K, Podgurniak M, Wit A. An immediate effect of PNF specific mobilization on the angle of trunk rotation and the Trunk-Pelvis-Hip Angle range of motion in adolescent girls with double idiopathic scoliosis - a pilot study. Scoliosis Spinal Disord. 2017;12:1-10.

16. Cobb J. Outline for the study of scoliosis. Instr Course Lect AAOS. 1948;5:261-75.

17. Rigo MD, Villagrasa M, Gallo D. A specific scoliosis classification correlating with brace treatment: description and reliability. Scoliosis. 2010;5:1.

18. Tanure MC, Pinheiro AP, Oliveira AS. Reliability assessment of Cobb angle measurements using manual and digital methods. Spine J. 2010;10: 769-74.

19. Maizlin ZV, Vos PM. How to measure scapholunate and Cobb's angles on MRI and CT. J. Digit Imaging. 2012;25:558-61.

20. Bunnell WP. Outcome of spinal screening. Spine. 1993; 18:1572-80.

21. Bonagamba GH, Coelho DM, Oliveira ASd. Inter and intra-rater reliability of the scoliometer. Braz. J. Phys. Ther. 2010;14:432-8.

22. Bunnell WP. An objective criterion for scoliosis screening. J. Bone Jt. SurgAm. vol. 1984;66:1381-7.

23. Shim J-H, Oh D-W, Lee G-W. The effects of thoracic flexibility exercise on vital capacity and chest expansion in patients with idiopathic scoliosis. Phys. Ther. Korea. 2002;9:145-56.

24. Kim J. Comparison of effects of ball - sling exercise and Schroth treatments in adolescents with idiopathic scoliosis. The Graduate School of Sports Science. Dankook University: Master's thesis; 2010

25. Rigo MD, Grivas TB. " Rehabilitation schools for scoliosis" thematic series: describing the methods and results. Springer; 2010.

26. Berdishevsky H, Lebel VA, Bettany-Saltikov J, Rigo M, Lebel A, Hennes A, et al. Physiotherapy 
scoliosis-specific exercises-a comprehensive review of seven major schools. Scoliosis Spinal Disord. 2016;11:20.

27. Pehrsson K, Bake B, Larsson S, Nachemson A. Lung function in adult idiopathic scoliosis: a 20 year follow up. Thorax. 1991;46:474-8.

28. Asher MA, Burton DC. Adolescent idiopathic scoliosis: natural history and long term treatment effects. Scoliosis. 2006;1:2.

29. Lehnert-Schroth C. Three-dimensional treatment for scoliosis: physiotherapeutic method for deformities of the spine: Martindale Press; 2007.

30. Rigo M, Quera-Salvá G, Villagrasa M, Ferrer M, Casas A, Corbella C, et al. Scoliosis intensive out-patient rehabilitation based on Schroth method. Stud Health Technol Inform. 2008;135:208.

31. Herling O. Clinical measurements, radiological and cosmetic improvements in a girl with adolescent idiopathic scoliosis treated with a Schroth rehabilitation program: a single case study. Scoliosis. 2009;4:1-2.

32. Hermann R, Mixon J, Fisher A, Maulucci R, Stuyck J. Idiopathic scoliosis and the central nervous system: a motor control problem. Spine. 1985; 10:1-4.

33. Focarile FA, Bonaldi A, Giarolo M-A, Ferrari U, Zilioli E, Ottaviani C. Effectiveness of nonsurgical treatment for idiopathic scoliosis. Overview of available evidence. Spine. 1991;16:395-401.

34. Weiss HR. The effect of an exercise program on vital capacity and rib mobility in patients with idiopathic scoliosis. Spine. 1991;16:88-93.

35. Wong MS, Mak A, Luk K, Evans J, Brown B. Effectiveness of audio-biofeedback in postural training for adolescent idiopathic scoliosis patients. Prosthet Orthot Int. 2001;25:60-70. 